\title{
Assessment of Impacts Caused by Granite Quarries on Vegetation: A Case Study in the Kalutara District
}

\author{
Gunarathna, M.D.A.M. , Ranwala, S.M.W. \\ Department of Plant Sciences, Faculty of Science, University of Colombo, Sri Lanka \\ *mdamil.gunarathna@gmail.com
}

\begin{abstract}
Granite quarrying has become a major business enterprise from which huge economic benefits are gained while neglecting the damage on the environment. In this study we investigated the effect of small and large scale granite quarries $(\mathrm{n}=2$ each) on neighboring individual plants and their communities. We compared foliar anatomy and stomata conductance of Macaranga peltata(MP) and Melastomamalabathricum(MM) sampled $(\mathrm{n}=6)$ from the edge and $\sim 700 \mathrm{~m}$ away from the quarries. Floristic details of the vegetation were enumerated using three $200 \mathrm{~m}$ transects at each site in which three plots $\left(10 \times 10 \mathrm{~m}^{2}\right)$ were set at the edge, $100 \mathrm{~m}$ and $200 \mathrm{~m}$ away from the quarry. Each plot had three $1 \mathrm{x} 1 \mathrm{~m}^{2}$ subplots to determine the herbaceous cover, soil physical properties and seed bank. Ecological dominance of species was determined using the Important Value Index (IVI) and the floral diversity was assessed using standard biodiversity indices. Statistics (t-test) using SPSS (16.0) was applied where appropriate. Wind-blown granite dust was a major problem which affected the foliar anatomy and physiological performance. Stomatal conductance (MP$113.17 \& 131.75 \mathrm{mmol}^{-2} \cdot \mathrm{s}^{-1}$ and MM- $149.00 \& 144.75 \mathrm{mmol} \mathrm{m}^{-2} \cdot \mathrm{s}^{-1}$ in large and small quarries respectively) was lower compared to unaffected leaves (MP-419.67 and MM-432.40 $\mathrm{mmol} \mathrm{m}^{-2} \mathrm{~s}^{-1}$ ). Stomatal size was small in affected leaves (MP-62.87 \& $62.81 \mu \mathrm{m}^{2}$ and MM$47.87 \& 47.05 \mu^{2}$ in large and small quarries respectively, compared to MP-115.37 and MM-74.27 $\mu^{2}$ ) but had an increased stomatal density (MP-1502.78, 1419.44 stomata/mm ${ }^{2}$ and MM-3113.89, 3244.44 stomata $/ \mathrm{mm}^{2}$ in large and small quarries respectively, compared to MP-846.67 and MM-875.56 stomata/ $\mathrm{mm}^{2}$ ).IVI indicatedTremaorientalisand Macarangapeltatadominate in the neighbourhood. Diversity indices increased at a distance from the quarry (Shannon Weiner diversity index - 0.601, 0.733, 1.298 in large quarries and $0.655,1.127,1.687$ in small quarries for edge, $100 \mathrm{~m}$ and $200 \mathrm{~m}$ respectively) indicating the limited species richness in the immediate neighbourhood. Establishment of invasive alien species Clidemiahirta, Panicum maximum, Dilleniasuffruticosaand Alstoniamacrophyllaat quarry edge also reflected the negative impacts of disturbances to the site. Soil seed banks of weeds exhibited the highest density at the edge and decreased towards the outside. Quarry edge had high soil temperature, low moisture content, low conductivity and acidic $\mathrm{pH}$. Impacts to the vegetation were similar irrespective of the category of granite quarries (small or large) as quarrying activity highly influenced the stomatal functions, and affect establishment of natural plant communities while adding weeds and invasive alien species.
\end{abstract}

Keywords: Quarrying activity, Impacts, Plants, Community

Proceedings of the International Forestry and Environment Symposium 2017 of the Department of Forestry and Environmental Science, University of Sri Jayewardenepura, Sri Lanka 